\title{
Nasal Rhinosporidiosis: A Case Study
}

\section{Begum Fouzia*, Shah Iftekar Ali and Gyaneshwari S}

Department of Microbiology, Shadan Institute of Medical Sciences, Hyderabad, Affiliated to NTRUHS, Vijayawada, India

\begin{abstract}
A 60 year old male presented with frequent episodes of nasal obstruction and epistaxis since 1 year. Strawberry appearance mass was observed in the left nostril, suspected to be rhinosporidiosis. Rhinosporidiosis is a chronic granulomatous, infective disease caused by Rhinosporidium seeberi having been known for more than hundred years. The lesion produces bulky, friable mucosal polyps commonly in the nasal cavity and nasopharynx. He gave history of bathing in ponds. He was treated by local surgical excision.
\end{abstract}

\section{Keywords: Polyps; Nasal; Rhinosporidium seeberi}

\section{Introduction}

The disease is generally found prevalent in Southeast Asian countries like southern India, Sri Lanka and South American continent, particularly Argentina and Brazil. The maximum incidence is seen in endemic areas of Indian subcontinent having warm climates. It is rare in Europe, North America and other continents and is not yet reported from Australia. It has been observed that $90 \%$ patients are from Asia, while South America accounts for less than 5 percent. From India, it has been extensively reported from Tamil Nadu, Kerala, Pondicherry, Andhra Pradesh, West Bengal and Chhattisgarh [1]. This disease is commonly seen in adult men with a male - female ratio of 3:1 - 4:1. The possible mode of transmission to humans is by direct contact with spores through dust, through infected clothing and fingers and through swimming in stagnant water $[1,2]$. The presumed mode of infection from the natural aquatic habitat of R. seeberi, is through the traumatised epithelium ('transepithelial infection') most commonly in nasal sites [3]

\section{Material and Methods}

Rhinosporidium seeberi has not been cultivated. Diagnosis depends on the demonstration of sporangia. Tissue sections stained with H\&E stain show large number of fungal spherules embedded in a stroma of connective tissue and capillaries. The spherules are $10-200 \mu \mathrm{m}$ in diameter and contain thousands of endospores about 6-7 $\mu \mathrm{m}[4,5]$.

Apart from history and clinical findings, a $10 \% \mathrm{KOH}$ mount of biopsied tissue from the lesion may give an indication of the diagnosis. However, histopathology is mandatory for the definitive diagnosis of Rhinosporidiosis, a typical feature being identification of the pathogen in its diverse stages of development.

\section{Results and Discussion}

Rhinosporidiosis is a granulomatous disease affecting the mucous membrane of nasopharynx, oropharynx, conjunctiva, rectum and external genitalia. Though the floor of the nose and inferior turbinate are the most common sites, the lesions may appear elsewhere too. Traumatic inoculation from one site to others is common [6]

A 60 year old farmer, presented with complains of frequent episodes of nasal obstruction and epistaxis since 1 year. No co-morbid conditions. He was a chronic smoker and occasional ethanolic. He had a history of bathing in ponds. Upon examination, a mass was noticed in the left nostril, reddish in color and strawberry like in appearance. The

Right nostril showed a roomy nasal cavity with greenish crust, suggestive of Atrophic Rhinitis.
Routine investigations were normal. Diagnostic nasal endoscopy showed a strawberry like vascular mass in the left nostril, attached to the septum. A CT scan was also taken which showed an anterior mass, with clearly demarcated borders. There was no invasion of surrounding tissues.

In the Microbiology laboratory, a wet mount of a biopsy specimen was prepared in $10 \% \mathrm{KOH}$ and observed under $40 \mathrm{x}$ magnifications. It revealed the presence of several spherical sporangia containing numerous sporangiospores in different stages of development, suggestive of Rhinosporidiosis (Figures 1 and 2). Histopathology using H\&E staining confirmed the diagnosis (Figures 3 and 4).

Though it appears to occur universally, rhinosporidiosis remains largely endemic in the Indian subcontinent. Since our patient had a history of bathing in ponds, we believe that this may be his source of contracting the infection. Patients usually present with a history

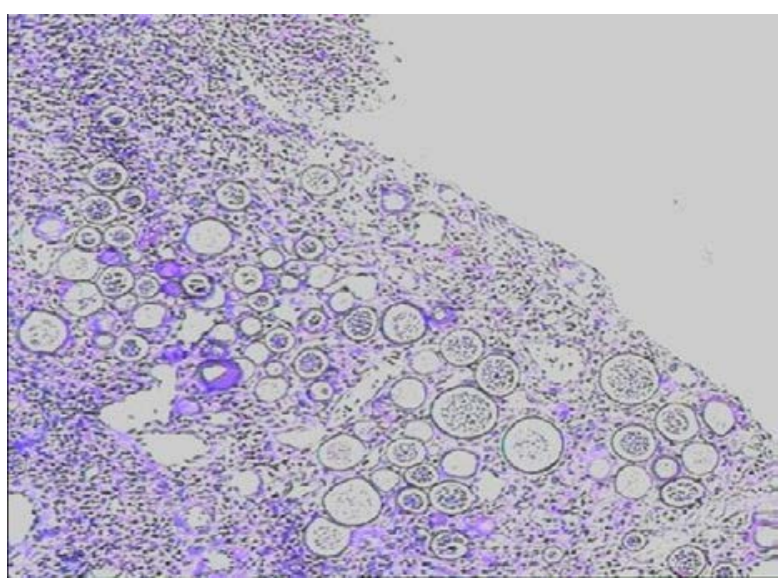

Figure 1: $10 \% \mathrm{KOH}$ mount.

*Corresponding author: Begum Fouzia, Assistant Professor, Department of Microbiology, Shadan Institute of Medical Sciences, Hyderabad, Affiliated to NTRUHS, Vijayawada, India, Tel:+919441040580; E-mail: fouzia.micro@gmail. com

Received April 19, 2015; Accepted May 28, 2015; Published May 31, 2015

Citation: Fouzia B, Ali SI, Gyaneshwari S (2015) Nasal Rhinosporidiosis: A Case Study. J Med Microb Diagn 4: 191. doi:10.4172/21610703.1000191

Copyright: $\odot 2015$ Fouzia B, et al. This is an open-access article distributed under the terms of the Creative Commons Attribution License, which permits unrestricted use, distribution, and reproduction in any medium, provided the original author and source are credited. 


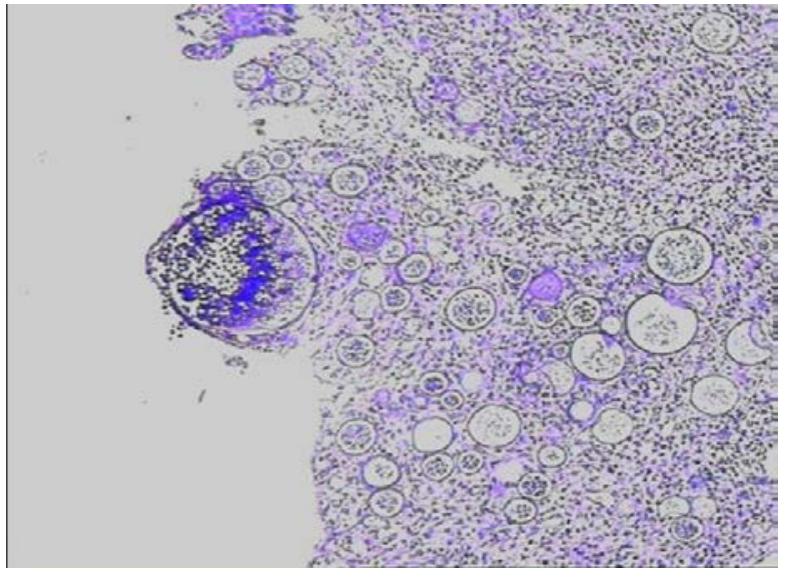

Figure 2: $10 \% \mathrm{KOH}$ of biopsy.

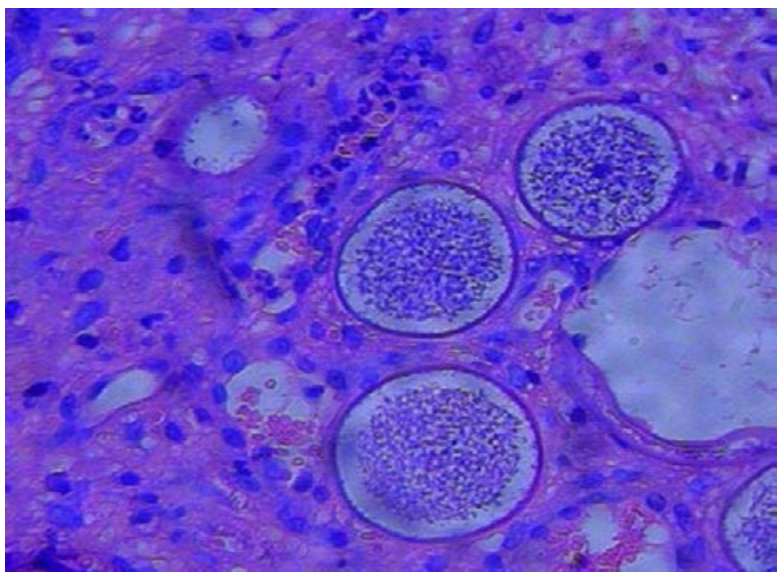

Figure 3: H\&E shows sporangia.

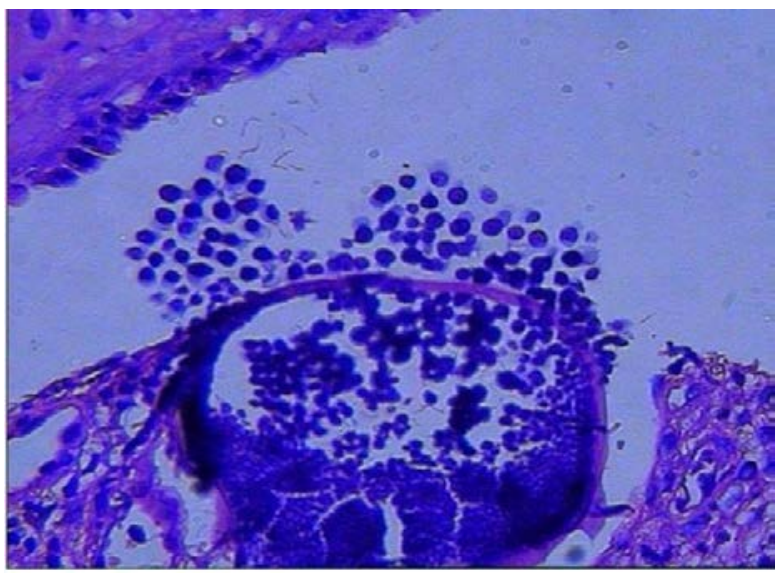

Figure 4: H\&E shows sporangiospores.

of a gradually growing nasal mass, occasional epistaxis, nasal itching, sneezing, and at times, post-nasal drip. On examination, Nasal Rhinosporidiosis is characterised by the presence of a single pedunculated polyp, multiple sessile polyps or a combination of both. Contrary to ordinary polyps which often arise from the middle turbinate, rhinosporidiosis frequently involves the mucosal lining of the naso-pharynx, anterior nares, inferior turbinate, septum or nasal floor. Therefore, nasal polyps originating from these locations should always be treated with a high index of suspicion.

The occurrence of rhinosporidiosis in river-sand workers, in India and in Sri Lanka, is particularly relevant to such a mode of infection, through abrasions caused by sand particles with the pathogen in the putative habitat - ground water. Trauma from $R$. seeberi contaminated stones used for mopping-up residual drops of urine is claimed to be responsible for anterior urethral rhinosporidiosis in the male. The absence of rhinosporidiosis in the sexual partners of these patients is cogent evidence that the disease is neither infectious nor contagious. Dissemination to the limbs, trunk and viscera has been described in a few cases, with a rare fatality especially when the brain was involved. In rhinosporidial lesions in the limbs, a notable feature has been the destruction of underlying bone. Rare cases of spontaneous regression of nasal polyps have been recorded [7].

The disease can be treated by radical surgery, either by excision or electrocautery of basic polyp. The medical treatment has not proved very effective except use of diamine diphenylsulphone (dapsone-DDS) [1]. With dapsone therapy, recurrences have been reported to have been minimized or prevented [8]. At present, there are no data on the development of resistance in $R$. seeberi to dapsone. As dapsone is the single most common drug used in the chemotherapy of rhinosporidiosis [9]. Surgical excision remains the mainstay of treatment. Wide, complete and meticulous excision of the polyp followed by thorough electro-cautery of the lesion's base is recommended.

Treatment: Local surgical excision was performed.

\section{Conclusion}

Nasal rhinosporidiosis continues to be a seldom suspected and seldom diagnosed disease in India. However, with reports of sporadic cases from all over the country and particularly from Hyderabad, (India) it is now imperative for clinicians in our city to consider rhinosporidiosis as a differential diagnosis when evaluating patients presenting with nasal growths and chronic epistaxis.

\section{References}

1. Chander J (2002) Text book of Medical Mycology. Second edition. Mehta Publishers. 154-162

2. Kamal MM, Luley AS, Mundhada SG, Bobhate SK (1995) Rhinosporodiosis Diagnosis by scrape cytology. Acta Cytol 39: 931-935.

3. Karunaratne WAE (1934) The pathology of rhinosporidiosis. J Path Bact XLII: 193-202.

4. Baveja CP (2014) Text book of Microbiology. Arya Publications 558.

5. Ananthanarayan and Panikers (2013) Text book of Microbiology. 9th edition Universities press.

6. Daharwal A, Banjara H, Singh D, Gupta A, Singh S, et al. (2011) A rare case of laryngeal rhinosporidiosis. J Laryngol Voice 1: 30-32

7. Arseculeratne SN (2002) Recent advances in rhinosporidiosis and Rhinosporidium seeberi. Indian J Med Microbiol 20: 119-131.

8. Nair KK (1979) Clinical trial of diaminodiphenylsulfone (DDS) in nasal and nasopharyngeal rhinosporidiosis. Laryngoscope 89: 291-295.

9. Arseculeratne SN (2009) the Chemotherapy of Rhinosporidiosis: A Review: J Infect Dis Antimicrob Agents 26: 21-27. 